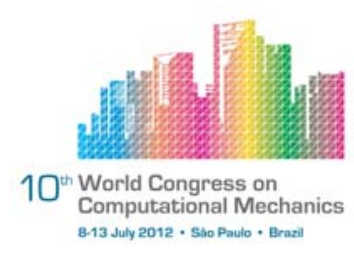

\title{
MACROSCOPIC NUMERICAL SIMULATION ON COMPRESSIVE BEHAVIOR OF RECYCLED AGGREGATE CONCRETE BASED ON IMAGE ANALYSIS
}

\author{
Tan $\mathrm{Li}^{1}$,Ciman Zhu ${ }^{1}$
}

${ }^{1}$ Department of Building Engineering, Civil Engineering School at the University Tongji, Shanghai, 200092, China (1_ltvip@tongji.edu.cn)

\begin{abstract}
As a kind of environmental friendly material, the recycled aggregate concrete (RAC) attracts extensive attention. The compressive behavior of it is main problem in study. Currently, one problem in study is how to create the macroscopic numerical analysis model of recycled aggregate (RA). In this paper RAC is considered as six-phase composite material, which include natural aggregate (NA), old mortar, new mortar, interface of NA and old mortar, interface of NA and new mortar and interface of old mortar and new mortar. In the problem of aggregate distribution, this paper use geometry information came from the failure surface of RAC specimen. Through numerical simulation to cube specimen section, this paper gets the uniaxial compression stress-strain curves and the process of cube concrete specimen section cracking. The analysis of results obtained following conclusions: considering RA as three-phase composite material (NA, old mortar, interface of NA and old mortar) could reflect the macro-cracking process in $R A$; The additional interface came from RA lead to RAC having more micro-crack than common concrete; The RA has coarse surface which let it combine with new mortar more firmly; The same elastic modulus of old mortar and new mortar let them having a similar displacement under a same stress, which inhibit cracking in interface of old mortar and new mortar.
\end{abstract}

Keywords: Recycled aggregate concrete, Numerical simulation, Image analysis

\section{INTRODUCTION}

Recycled aggregate concrete (RAC) is a kind of composite material. Most micro-mechanics models of concrete are composed of natural aggregate (NA), recycled aggregate (RA), mortar, interface of NA and mortar and interface of RA and mortar. Compared with common concrete RAC has new components RA and the interface of RA and mortar. Therefore, the analysis method of common concrete can be used on RAC. The macro-structure model cannot reflect the nonlinear characteristics, so that macroscopic numerical simulation of concrete can be a complement to the real experiment and provide some advice to value-taking of concrete mechanical parameters. Concrete numerical analysis exists following methods: random property model, random aggregate model and reconstruction model based on image analysis. Random mechanics model describes 
heterogeneous of concrete by Weibull random function and assigned different mechanical parameter to different element. The best advantage of random mechanics model is the heterogeneous of concrete can be considered sufficiently. In random aggregate model ${ }^{[1-5]}$, It is considered that concrete composed of aggregate, mortar and interface. And the aggregate could be generated by a random function. This method takes the random of aggregate distribution into account. Reconstruction model base on geometry information of aggregate, mortar and interface extracted from the section of concrete. The shape and distribution of aggregate are close to real concrete. All above methods use statistics and random to build the micro-structure model of concrete. Although the distribution and the shape of aggregate in numerical are same as in real concrete structure, there also exist many difference. For this reason, reconstruction model based on image analysis, which is the model closest to the real concrete structure, is used by this paper.

The early 1980s, Morgan etc ${ }^{[1]}$ using CT scan little concrete specimen get the section

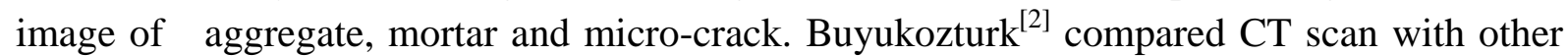
method find X ray and CT scan are effective. Daniel etc ${ }^{[3]}$ using digital image analyzed the expanding of crack in Prism compression tests. Jean etc ${ }^{[4,5]}$ studied the applications of automatic image analysis in civil engineering which is suitable to access many morphological parameter. Anne etc ${ }^{[6]}$ using digital image analyzed each phases in the section of concrete. Man etc ${ }^{[7]}$ use CT system scans concrete specimen layer by layer to get a 3D micro-structure image and based on which generated nodes and elements, then built a micro-structure numerical model of concrete. There also exists some numerical analysis studies on $\mathrm{RAC}^{[8,9]}$, but the method of built numerical micro-structure model of concrete based on image analysis is rare. Abbas etc ${ }^{[10]}$ analyzed RAC section image by numerical method and acquired the content of each component material in RAC.

In this paper the geometry information of cube concrete specimen section came from the failure surface of RAC specimen. A program compiled by APDL language of software ANSYS was applied to build micro-structure numerical model of RAC. From the Fig.1, it could be seen that the failure of RA is complex, so that considering the internal composition of RA is necessary. Therefore, in this paper RAC is considered as three-phase composite material, which include NA, old mortar, new mortar, interface of NA and old mortar, interface of NA and new mortar, interface of old mortar and new mortar. Compared with common RAC model the RA is considered as three-phase composite material, which includes NA, old mortar, interface of NA and old mortar. 


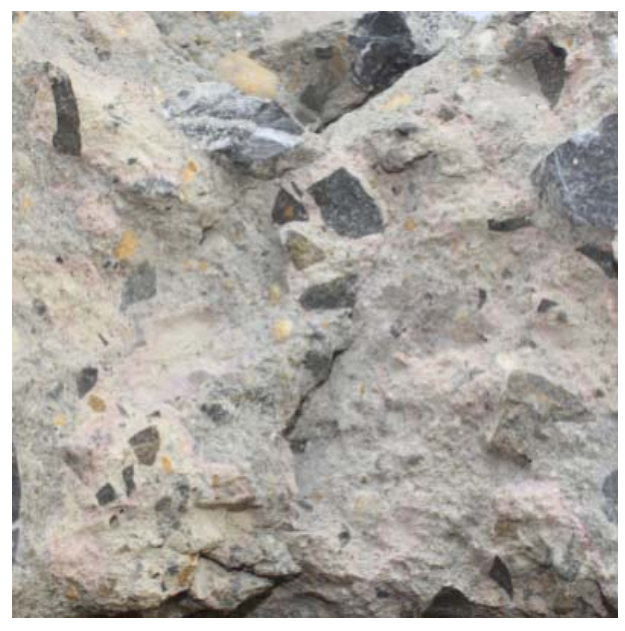

Fig.1 Failure surface of RAC specimen

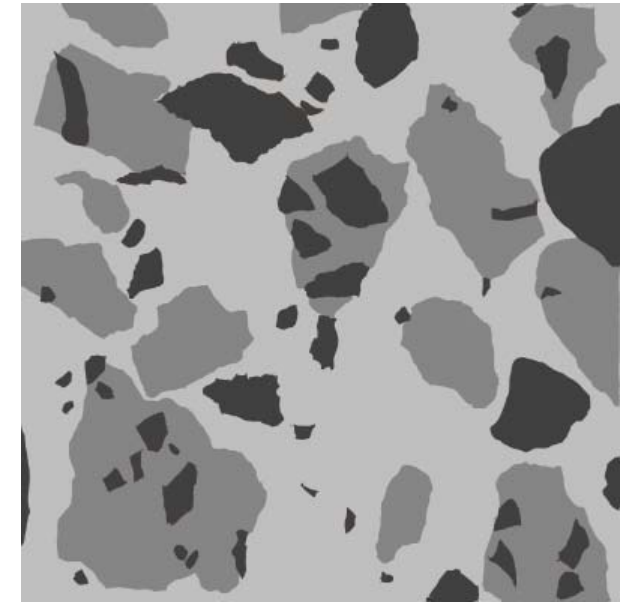

Fig.2 geometric model of RAC specimen

\section{EXPERIMENT PLAN AND EXPERIMENT PROGRESS}

Firstly, poured a large common concrete board and some stand cube concrete specimen at the same time. By experiment obtained basis mechanics parameters of this board. Then broke the board to a certain size and sieved them according to need grading. In this way, the RA was obtained. Before poured RAC, for distinguishing between the new mortar and the old mortar in RA, surface of RA was dyed by red ink. Then dried it to a state of saturated surface dry. Finally, some stand cube RAC specimens were poured. At the time curing age 28 days obtained the basis mechanics parameters of the RAC by experiment. After experiment a crushed RAC specimen was selected. Cleaned the failure surface of this specimen and obtained the image of this surface. By following stages, extracted the geometric boundary of NA and RA according to the color of them then simulated the compressive behavior of RAC. Firstly, by a color threshold red color parts, which is stand for RA boundary, were separated out from the image. Then the remained image was changed to gray. By a gray threshold the NA and RA were separated. By this way some coarse boundaries could be obtained. Then these boundaries were refined by hand. By this way some smooth boundaries could be obtained. Secondly, boundaries were modified from single line to double lines. The part between double lines is interface. At this stage the geometric model was built. Finally, imported this model to numerical analysis software and mesh it. Through numerical simulation of uniaxial compression experiment analyzed mechanical performance of RAC

\section{CUBE COMPRESSION PERFORMANCE SIMULATION}

\subsection{Finite element model}

The dimension of RAC cube specimen used in this research is $150 \mathrm{~mm} \times 150 \mathrm{~mm} \times$ $150 \mathrm{~mm}$. The selected failure surface of it is showed in Fig.1. In Fig.1, black parts are NA, red 
parts are old mortar and gray parts are new mortar. By image analysis software the boundary information was extracted from the image of failure surface. Adding $0.3 \mathrm{~mm}$ width interface between all components, the final RAC section geometric model was created which was showed in Fig.2, In Fig.2 the $\mathrm{x}$ direction is horizontal direction, the $\mathrm{y}$ direction is vertical direction and $\mathrm{z}$ direction is thickness direction. Then this model was extended $1 \mathrm{~mm}$ along its thickness to get a $150 \mathrm{~mm} \times 150 \mathrm{~mm} \times 1 \mathrm{~mm}$ slight plate. Then imported it to ANSYS and got corresponding finite element model.

In the numerical model the NA particle size is $5-25 \mathrm{~mm}$; the RA particle size is 25-50mm; The mass ratio of RA replacing total concrete is $40 \%$. Every RAC component material use Solid65 element of ANSYS. The total element number is 20,716 which could be seen in Fig.3. In these elements the NA element number is 2,486; the old mortar element number is 5,522; the new mortar element number is 9,317; the interface number of NA and old mortar is 884; the interface number of NA and new mortar is 1,096; the interface number of old mortar and new mortar is 1,411. In Fig.3 the definition of coordinate axis equal to the definition of coordinate axis in Fig.2. In Fig.4 applied following boundary conditions. The displacements of nodes on the back of this model were set to 0 . The displacements of nodes on the front of this model were coupled. On the top of this model the $\mathrm{x}$ direction displacement was set to 0 . On the bottom of this model $\mathrm{x}$ direction displacement and $\mathrm{y}$ direction displacement were set to 0 . The analysis type selected static analysis and the convergence criteria selected displacement convergence criterion. The convergence accuracy is $0.5 \%$. The iterative method selects full Willam and Warnke iterative method. When the numerical simulation starts, apply displacement load at the top of numerical model along negative y direction.

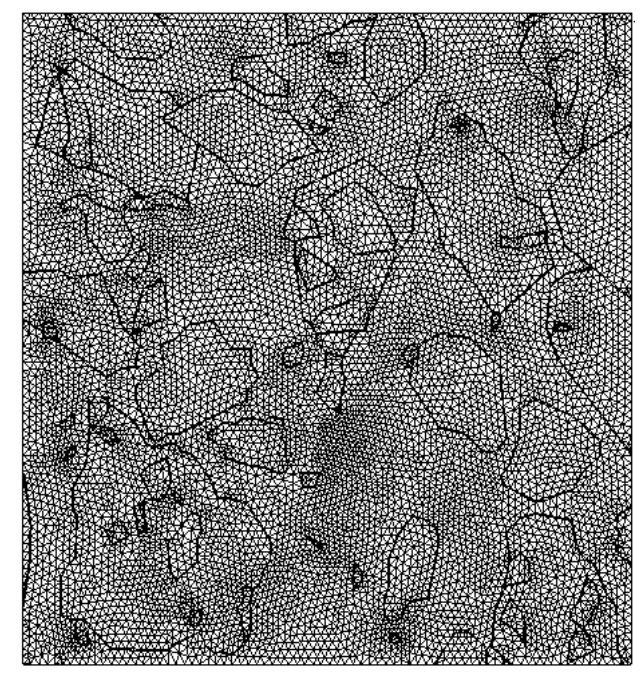

Fig.3 Numerical model

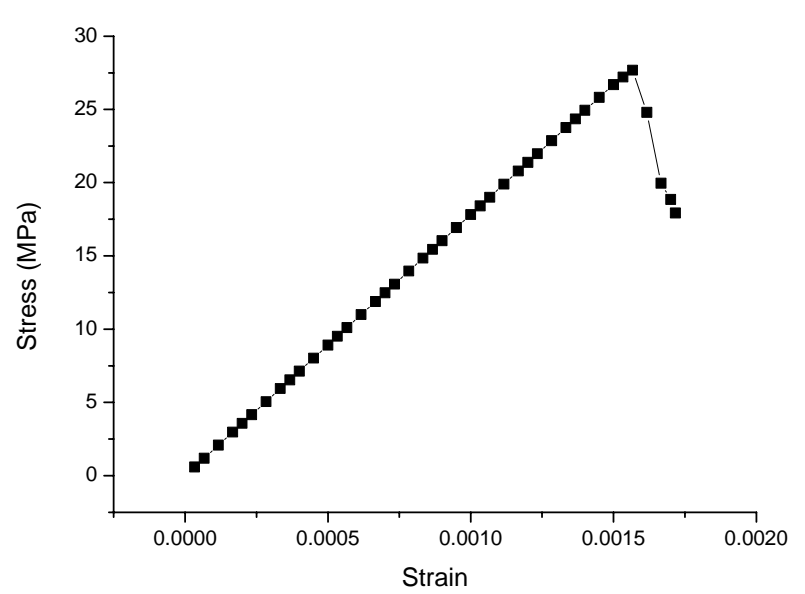

Fig.4 Stress-strain curve of uniaxial compressive
strength

\subsection{Selection of micro-constitutive and mechanic parameter}

Considering the RAC is a brittle material, failure criteria selected the failure criterion of 
Willam and Warnke failure criteria ${ }^{[11]}$ and ultimate tensile stress criteria. The stress state of concrete is divided to four Regions $\mathrm{T} / \mathrm{T} / \mathrm{T}, \mathrm{T} / \mathrm{T} / \mathrm{C}, \mathrm{T} / \mathrm{C} / \mathrm{C}$ and $\mathrm{C} / \mathrm{C} / \mathrm{C}$ based on principal stress symbol ( $\mathrm{T}$ express tension and $\mathrm{C}$ express compression). At $\mathrm{C} / \mathrm{C} / \mathrm{C}$ state, when the failure criterion of Willam and Warnkeis achieved, the material is considered failure. At other states, when a principal stress component exceeds ultimate tensile stress, the material broke along this principal stress component direction ${ }^{[12]}$. After cracking two coefficients are used to indicate the Shear loss at crack, which are shear transfer coefficients $\beta_{t}$ for an open crack and shear transfer coefficients $\beta_{c}$ for a closed crack. Mechanical parameters of mortar, aggregate and interface were obtained by comparing mechanical index with analysis result of numerical model. Every component material mechanical parameter showed in table 1.

Table 1 component materials mechanic parameter of RAC

\begin{tabular}{ccccccc}
\hline Material & $\begin{array}{c}\text { elastic } \\
\text { modulus } \\
\text { (GPa) }\end{array}$ & $\begin{array}{c}\text { Poisson's } \\
\text { ratio }\end{array}$ & $\begin{array}{c}\text { Compressive } \\
\text { strength } \\
(\mathrm{MPa})\end{array}$ & $\begin{array}{c}\text { Tensile } \\
\text { strength } \\
(\mathrm{MPa})\end{array}$ & \multicolumn{2}{c}{$\begin{array}{c}\text { Shear } \\
\text { transfer } \\
\text { coefficients }\end{array}$} \\
\hline NA & 31 & 0.16 & 130 & 10 & 0.5 & 0.95 \\
Old mortar & 17 & 0.22 & 72 & 6.7 & 0.5 & 0.95 \\
$\begin{array}{c}\text { New mortar } \\
\text { Interface of NA and old }\end{array}$ & 16 & 0.22 & 68 & 6.0 & 0.5 & 0.95 \\
$\begin{array}{c}\text { mortar } \\
\text { Interface of NA and new } \\
\text { mortar }\end{array}$ & 9 & 0.20 & 36 & 3.2 & 0.5 & 0.95 \\
$\begin{array}{c}\text { Interface of old mortar and } \\
\text { new mortar }\end{array}$ & 9 & 0.20 & 38 & 3.1 & 0.5 & 0.95 \\
\hline
\end{tabular}

\subsection{Result of simulation and analysis}

Analysis of macro stress-strain curve. Fig.4 shows the relationship of macro compressive stress and macro compressive strain in the simulation of RAC specimen uniaxial compression experiment. Referenced distance used in macro-strain measurement is $150 \mathrm{~mm}$. The Macro-stress was obtained by summing of stress of each node on top side of the specimen. From Fig.4, it could be seen that the stress-strain is almost linear and when the ultimate stress was exceeded the curve sharply decline. The feature that this curve appears is obvious elastic brittle characteristic. Considering the cracking showed in Fig.5, it could be seen that at the initial stage of the curve, the stress state of some relative weak interface elements archived failure criteria and broke. But because of these elements are relative weak and the number is few, released energy is few. Therefore the curve maintains a good linear relationship. When the average stress of this specimen was close to ultimate stress, with the increasing of load, many elements came into failure state. In this stage, cracks arose and were interconnected. At the same time the stress and strain relationship appeared obvious nonlinear. The Ultimate stress of this specimen is $27.67 \mathrm{MPa}$ and corresponding strain is 0.00157 . After ultimate stress, failure elements were connected into a macro-crack and the specimen lost compressive strength. The macro stress-strain curve of RAC specimen sharply drops after 
ultimate stress. The reason of it could be the interface in RA lead to RAC has more weak elements than common concrete. It is also reflected in the final crack image that RAC is more broken than common concrete.

Analysis of crack development. Fig. 5 shows the cracking process of RAC cube specimen under different strain. It could be seen from Fig.5 (a) that in the beginning of applying load crack was few. Only some elements at interface achieved tensile strength. The earliest failure element was the interface element of NA and mortar. The reason of it could be the interface of old mortar and new mortar is not easy cracking compared with interface of NA and mortar in specimen. Because of the RA has coarse surface which let it could combine with new mortar more firmly. And both the old mortar and new mortar have same elastic modulus which let them under a stress have same deformation. It means a continuous displacement between them inhabited cracking. From Fig.5(b), it is could be seen that with the increase of load, the failure element became more and more. Crack extended along interface. Gradually, some cracks which encompassed NA and old mortar appeared. At the same time some NA and mortar closing to interface started cracking. From this stage the number of failure element in interface increased slowly but the number of failure element in mortar increase sharply. From Fig.5(c) it is can be seen that with the sustained increase of load, some elements far away from interface started cracking and these cracks connected into a macro-crack. In another corner a new macro-crack started forming. From Fig.5 (d), it could be seen that with the increase of load, macro-cracks extended and became wider .At the same time more elements cracked. At last the macro-crack extended throughout the specimen and the specimen lost compressive bearing capacity. Closer look Fig.5 (d), it could be seen that the macro-crack extended in RA is complex. The extending of macro-crack in RA is effected not only by the coarse surface of RA which make it can easily combine with mortar around it, but also by the NA distribution in RA which let the material property of RA is inhomogeneous in every direction.

From the whole cracking process, it could be seen that the cracking process of RAC cube specimen based on the type of failure element and the form of macro-crack could be divided to three stages. The first stage started from strain equal to 0.0004 to strain equal to 0.0015. The feature of this stage is crack mainly concentrated on interface. The second stage started from strain equal to 0.0015 to strain equal to 0.00156 . The feature of this stage is a macro-crack appears and cracks extend to mortars around the macro-crack. The final stage started from strain equal to 0.00156 to strain equal to0.00172. The feature of this stage is the old macro-crack extended and new macro-crack appear till one of them extend throughout the specimen. At the beginning of loading the cracking started on interface elements. In this time the aggregate and mortar stress-strain relationship were linear. The macro-crack extended almost along various interface. The final cracks, which are showed in Fig.5 (d), were concentrated on the right and left area of specimen. And two main cracks separated them to two triangle failure part. Cracking areas are consistent with distribution of principal tensile stress component. It accord with actual failure characteristics of RAC cube specimen. Obviously, they are typical cracking of ultimate tensile stress. From above analysis we can think that the failure of specimen is come from the crack of interface which extended throughout the specimen at the end. In this progress, the composition of RA has some effect 
on crack extended.

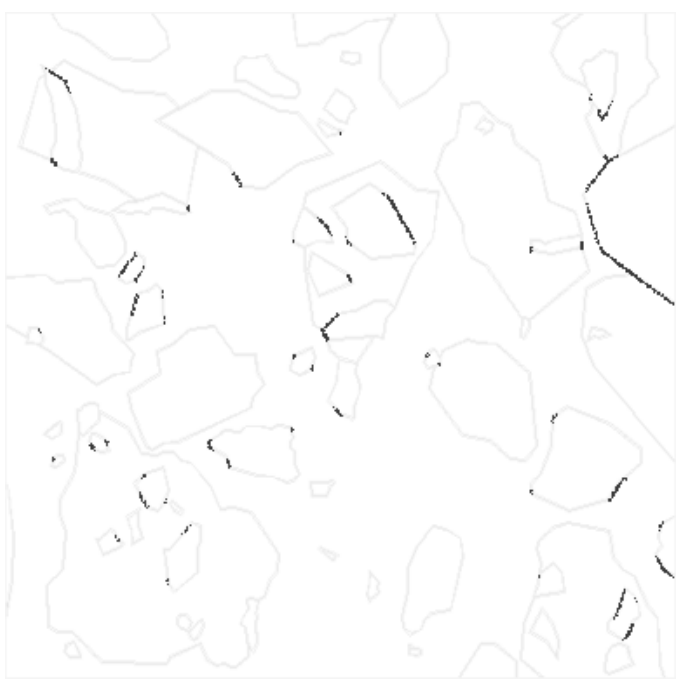

(a) Strain $=6.667 \mathrm{e}-4$

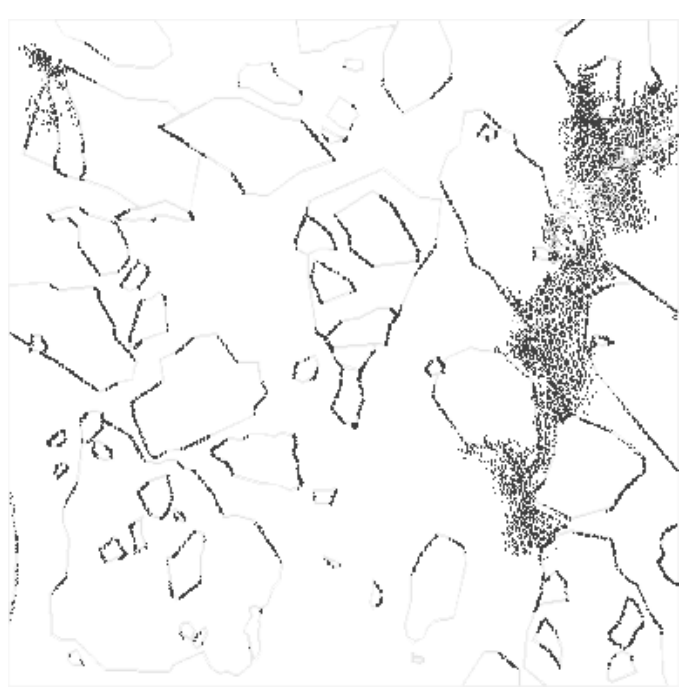

(c) Strain $=1.62 \mathrm{e}-3$

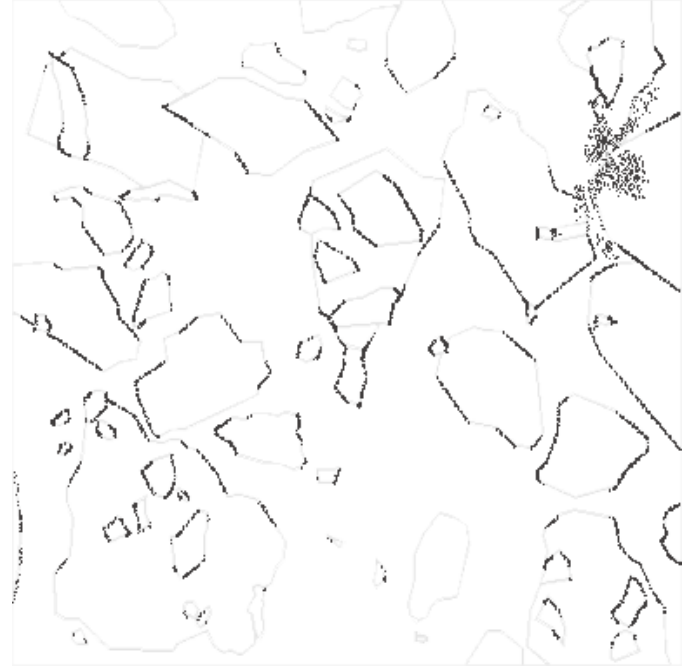

(b) Strain $=1.567 \mathrm{e}-3$

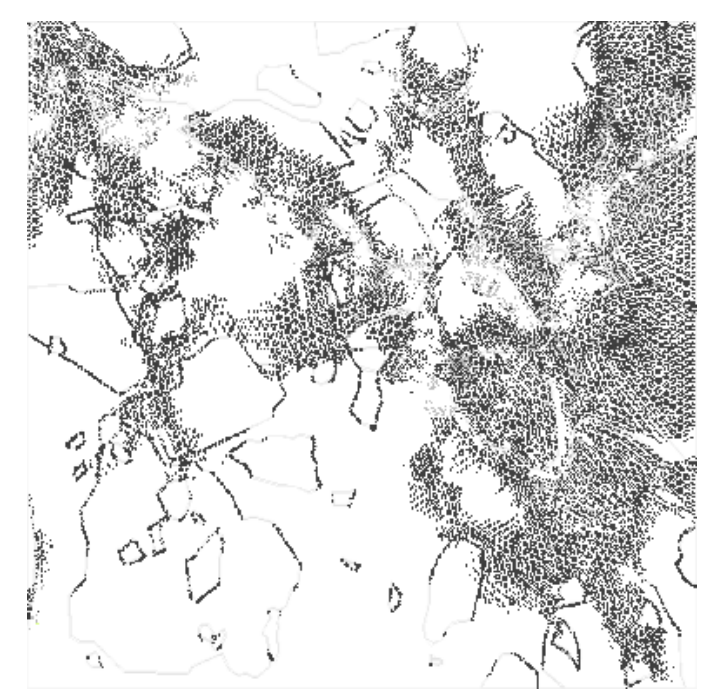

(d) Strain $=1.72 \mathrm{e}-3$

Fig.5 cracking process of RAC

\section{CONCLUSIONS}

This paper using image analysis software extracted geometry information from the failure surface of RAC cube specimen as well as using numerical analysis software created six-phase material model. By using this numerical model this paper analyzed the RAC mechanic performance under uniaxial compression and obtained following conclusions:

(1)The distribution of NA in RA has certain effect in macro-cracks extending in RA. Consider RA as three-phase composite material (NA, old mortar, interface of NA and old mortar) could reflect this effect. Many crack in RA start from the interface of NA and old 
mortar. Then extend gradually to mortar around it.

(2) The introduction of interface in RA lead to the increasing of total interface in RAC. This is a reason that in stress-strain curve of RAC specimen when the average compressive stress of specimen exceeded ultimate stress the curve sharply drops. Because cracking in interface is more easily taken place, RAC has more micro-crack than common concrete under a same load. It is reflected in the final failure image- $\mathrm{RAC}$ is has more macro-cracks than common concrete.

(3) Compared with the interface of NA and mortar, the interface of old mortar and new mortar is not easily cracking in specimen. The main reason of it could be the RA has coarse surface which let it could combine with new mortar more firmly. The other reason is both the old mortar and new mortar have similar elastic modulus which let them go through similar deformation under the same stress, namely continued displacement between them, which inhabit the cracking.

\section{REFERENCES}

[1] Morgan L, Ellinger H, Klinksiek R, et al. Examination of Concrete by Computerized Tomography. ASI Journal 1980, 77( 1) : 23-27..

[2] Buyu Kozturk O. Imaging of Concrete Structures . NDT\&E International 1998, 31( 4) : 233-243.

[3] Daniel C, Jan G M, Van M. Analysis of compressive fracture of three different concretes by means of 3D-digital image correlation and vacuum impregnation.Cement \& Concrete Composites 2010,32:281-290

[4] Jean L C. Why automatic image analysis? An introduction to this issue. Cement \& Composites 2001,23:127-131

[5] Jean L C, Liliane C, Michel C, et al. Some fields of applications of automatic image analysis in civil engineering. Cement \& Concrete 2001,23:157-169

[6] Anne S D, Michel C, Liliane C, et al. Study of phase dispersion in concrete by image analysis. Cement \& Composites 2001,23:215-226

[7] H K Man, J G M. van Mier. Damage distribution and size effect in numerical concrete from lattice analyses. Cement \& Concrete Composites 2011,33:867-880

[8] Hoon L, Ji H K, Kwan H , et al. Application of DEM model to breakage and liberation behaviour of recycled aggregates from impact-breakage of concrete waste. Minerals Engineering 2008,21:761-765

[9] Jianzhuang X, Jingwei Y, Luming S. FEM simulation of chloride diffusion in modeled recycled aggregate concrete. Construction and Building Materials 2012,29:12-13

[10] A Abbas, D Fathifazl, B Fournier, et al. Quantification of residual mortar content in recycled concrete aggregate by image analysis. Materials characterization 2009; 60; 716-726

[11] William, K J Warnke, E P: Constitutive model for the triaxial behaviour of concrete. IABSE 1974.

[12] Song Y. Multiple Concrete Material Constitutive and Failure Criteria. Beijing 2002(in Chinese) 